\title{
Health Conditions and Functional Status in Adults with Autism: A Cross-Sectional Evaluation
}

\author{
Robert J. Fortuna, $M D, M P H^{7}$, Laura Robinson, $\mathrm{MPH}^{2}$, Tristram H. Smith, $P h D^{2}$, Jon Meccarello, $P h D^{2}$, \\ Beth Bullen, BSN ${ }^{2}$, Kathryn Nobis, BS ${ }^{2}$, and Philip W. Davidson, PhD' \\ ${ }^{1}$ Center for Primary Care, Department of Internal Medicine and Pediatrics, University of Rochester School of Medicine and Dentistry, Rochester, NY, \\ USA; ${ }^{2}$ Division of Neurodevelopmental and Behavioral Pediatrics, Department of Pediatrics, University of Rochester School of Medicine and \\ Dentistry, Rochester, NY, USA.
}

BACKGROUND: Children and adolescents with autism spectrum disorder (ASD) have many well-known health concerns, yet health conditions in adults with ASD remain poorly defined.

OBJECTIVE: To examine health conditions and functional status in adults with ASD and identify factors associated with health and functional status across age cohorts.

DESIGN AND SUBJECTS: We collected cross-sectional data from 255 adult subjects aged 18 to 71 years with ASD using the Rochester Health Status Survey IV (RHSS-IV), a 58-item validated survey instrument. We used the National Health and Nutritional Examination Survey and National Health Interview Survey to provide comparative prevalence rates in the general population.

RESULTS: Compared to the general population, young adults aged 18-29 with ASD had a substantially higher prevalence of seizure disorder (11.2\% vs. $1.4 \%$; $p=$ 0.002), depression ( $16.4 \%$ vs. $6.4 \%$; $p=0.007$ ), hypertension ( $12.9 \%$ vs. $6.3 \% ; p=0.05)$, and allergies $(39.7 \%$ vs. $8.4 \%$; $p<0.001)$. In contrast, young adults with ASD had considerably lower rates of sexually transmitted illness (STI) (0.9 \% vs. $4.3 \% ; p=0.03)$, tobacco use $(5.2 \%$ vs. $31.9 \% ; p<0.001)$, and alcohol misuse $(0.9 \%$ vs. $11.9 \% ; p<0.001)$. Adults 40 and over with ASD also had higher rates of seizure disorder $(29.2 \%$ vs. $1.7 \%$; $p<0.001)$, lower tobacco use (2.8\% vs. $24.5 \%$; $p<0.001$ ), and lower alcohol misuse (1.4\% vs. $18.2 \%$; $p<0.001)$ compared to the general population. Amongst the $55 \%$ of participants with a documented IQ score, $91 \%$ had an intellectual disability (IQ < 70). Within the cohort aged 40 years old and older, only $54.2 \%$ were independent with eating, $43.0 \%$ independent with dressing, and $43.1 \%$ independent with bathing. Lower IQ and depression were associated with lower functional status.

CONCLUSIONS: Adults with ASD have a high prevalence of seizure disorders and depression, but low rates of STIs, tobacco use, and alcohol misuse. Within our cohort, the majority of older adults with ASD required some assistance with activities of daily living.

Received January 29, 2014

Revised June 1, 2015

Accepted August 24, 2015

Published online September 11, 2015
KEY WORDS: autism; autism spectrum disorders; health status; functional status.

J Gen Intern Med 31(1):77-84

DOI: $10.1007 / \mathrm{s} 11606-015-3509-\mathrm{x}$

(c) Society of General Internal Medicine 2015

\section{BACKGROUND}

Autism was first described in case reports over 70 years ago. ${ }^{1}$ Since that time, autism has become increasingly recognized and is now considered the most common neurodevelopmental disability in childhood, estimated to affect one in 68 children. ${ }^{2}$ Autism spectrum disorders (ASD) are defined by impairments in social communication, restricted interests, and repetitive patterns of behavior. ${ }^{3-7}$ Although extensively studied in pediatric age groups, there has been a relative paucity of literature examining ASD in adulthood. ${ }^{8,9}$

Children and adolescents with ASD have many well-known health concerns, including psychiatric co-morbidities, sleep disturbances, and gastrointestinal conditions, ${ }^{5,7}$ yet health conditions and trajectories in adults with ASD remain underresearched, despite the large size of this population. ${ }^{10-14}$ One recent study examined health conditions in young adults with ASD in several large quaternary hospitals and found a high prevalence of epilepsy, schizophrenia, and bowel disorders. ${ }^{15}$ However, little is known about health conditions in an older community population of adults with ASD.

Functional status of adults with ASD also remains poorly understood. In general, adaptive functioning in adults with neurodevelopmental disorders declines with advancing age in different ways from the general population, ${ }^{16}$ but this has not been examined in adults with ASD. Many adults with ASD develop new skills with age that allow them to thrive independently throughout life. Others require more supportive environments. Examining functional status is critical towards improving adaptive functioning and supporting independence for different cohorts of adults with ASD.

Adults with ASD have reported lower satisfaction with patientprovider communication and higher unmet healthcare needs compared to non-autistic adults. ${ }^{17}$ To better understand the health of adults with ASD, we undertook a study to (1) examine the health and functional status in adults with ASD in several 
different age groups; (2) examine the prevalence of medical and psychiatric conditions in adults with ASD and to compare the prevalence to the general population; and (3) identify factors associated with worsening health and functional status.

\section{METHODS}

\section{Rochester Health Status Survey (RHSS)}

We collected cross-sectional data from adults aged 18 years and over with ASD using the Rochester Health Status Survey IV (RHSS-IV). The RHSS-IV is a 58-item validated survey of health and functional status in adults with intellectual or developmental disabilities (IDD). ${ }^{18}$ The survey instrument was previously validated using three different reviewers and a developmental disabilities geriatrician. ${ }^{18}$ The survey instrument has five sections: (1) demographics, (2) general health status health, (3) medical conditions, (4) functional status, and (5) health services utilization. ${ }^{19,20}$

\section{Study Sites}

We collected data at eight different sites, including a large primary care network in Rochester, NY. Sites were included based on their ability to collect data on adults with a broad range of intellectual and neurodevelopmental disabilities, including ASD. Data were collected from nonprofit agencies and primary care offices located in Rochester, NY; Batavia, NY; Syracuse, NY; Brewster, MA; St. Louis, MO; Torino, Italy; and Israel. The majority of cases $(205,80.4 \%)$ came from a primary care network in Upstate NY, which included 28 practices. In addition to our primary analyses, described later, we also performed a sensitivity analysis including only sites from the Rochester area.

\section{Age Groups}

To examine the association of age with health status and allow for comparison with normative samples, we divided our sample into an 18-29 year old group, which included almost half of the subjects, and two older groups that were similar to each other in size: $30-39$ years old and 40 years old and over.

\section{Identification of ASD Subjects}

We identified subjects with ASD based on a multi-step process. Potential cases were first identified based on either disease registries or a broad query of the electronic health record using ICD-9 codes of 299.xx on the problem list. Because of their ages, participants received their ASD diagnosis many years prior to the changes in the DSM-5 definition of ASD. Hence, some conditions, such as pervasive developmental disorder (PDD-NOS), may or may not have been associated with ASD. The diagnosis of ASD was subsequently confirmed upon manual chart abstraction. Only subjects with a confirmed diagnosis of autism, ASD, or Asperger's syndrome were included in the analyses.
Medical records from the Rochester, NY cohort were identified initially based on an electronic query of the electronic health record, and were subsequently manually abstracted by the fifth author, an experienced nurse. Medical records of Israeli participants were identified from disease registries from people receiving their community-based care from the Ministry of Social Affairs and Social Services' Division for the Care of People with Intellectual Developmental Disabilities. The remaining sites similarly identified subjects with ASD from disease registries.

\section{RHSS Data Abstraction}

At all sites, data were collected from chart review by dedicated research nurses who had received training in the use of the RHSS-IV survey instrument for data abstraction. Chart review and data abstraction required approximately 60 minutes per subject. The research nurses confirmed the diagnoses through direct chart review prior to manual data archiving. No data were collected from patients directly or from proxy participants. A physician experienced with intellectual and developmental disabilities was available to assist with data collection. Once collected, the data were double-entered into two separate Microsoft Access databases and then compared for any inconsistencies using SAS version 9.3. Any inconsistencies were reconciled with the primary paper survey.

\section{RHSS-IV Variable Creation}

Within the RHSS-IV, overall health was rated as (1) excellent, (2) good, (3) fair, or (4) poor. We combined health status into either excellent/good or fair/poor for analyses. We examined specific health conditions in multiple broad categories, including heart and circulatory diseases, pulmonary diseases, endocrine/ metabolic diseases, gastrointestinal diseases, neurologic diseases, genito-urinary and kidney diseases, dental diseases, and musculoskeletal conditions. The existence of a specific health condition was evaluated based on questions inquiring about individual health conditions within each category. We analyzed health conditions based on the prevalence of the condition since the age of 21 or if the condition appeared within the last 24 months. Functional ability was based on subjects' abilities to perform their activities of daily living (ADL). Each ADL was recorded as either: (1) independent, (2) requiring supervision or verbal prompt, (3) requiring physical assistance, or (4) totally dependent.

We determined IQ based on chart abstraction. When available, IQ was obtained from prior psychological evaluation. IQ was available for $55.3 \%$ of the sample. Missing data are included in Table 1 and incorporated in the percentages.

\section{National Health and Nutrition Examination Survey (NHANES) and National Health Interview Survey (NHIS)}

We used NHANES and NHIS to provide prevalence estimates for common health conditions in the general population. NHANES is a multistage probability survey designed to assess 
Table 1 Characteristics of Adults with Autism Spectrum Disorders Included in the RHSS-IV Sample

\begin{tabular}{ll}
\hline Characteristic & ASD \\
& N=255 (100 \%) \\
\hline Age (years) & \\
18-29 & $116(45.5)$ \\
$30-39$ & $67(26.3)$ \\
40 and Over & $72(28.2)$ \\
Gender & $63(24.7)$ \\
Female & $192(75.3)$ \\
Male & $13(5.1)$ \\
IQ & $78(30.6)$ \\
IQ>70 (Normal/Borderline) & $50(19.6)$ \\
IQ 40-69 (Moderate) & $114(44.7)$ \\
IQ < 39 (Severe / Profound) & \\
IQ Not available & $17(7.4)$ \\
Living Arrangement & $110(47.8)$ \\
Independent & $103(44.8)$ \\
With Family & \\
Supervised Setting & $179(78.2)$ \\
Region & $50(21.8)$ \\
City & \\
Town or Rural Community & $205(80.4)$ \\
Site & $16(6.3)$ \\
Rochester, NY & $5(2.0)$ \\
Upstate New York* & $10(3.9)$ \\
Massachusetts & $19(7.4)$ \\
St. Louis, MO & \\
Israel and Italy & \\
\hline
\end{tabular}

*Includes Sites from Syracuse and Upstate NY Region

the health and nutritional status of adults and children in the United States. $^{21}$ NHANES combines both interviews and physical examinations and is conducted in 2-year cycles. Similarly, NHIS is a cross-sectional household interview survey that is performed continuously throughout the year. ${ }^{22}$ NHIS also follows a multistage probability design that permits the representative sampling of households. Both surveys are conducted by the National Center for Health Statistics (NCHS) and the Center for Disease Control and Prevention (CDC). ${ }^{21,22}$

We used NHANES 2009-2010 and NHANES 2011-2012 for all measures of disease prevalence except for estimates of seizure and migraine prevalence, which were not available in NHANES. We used NHIS 2013 to estimate the prevalence of seizures and migraines in the general population. We excluded persons with ASD from our general population data.

\section{NHANES and NHIS Variable Creation}

Within NHANES and NHIS, we defined almost all conditions based on the question "Has a doctor or health professional ever told you that you had or have ?" We defined alcohol misuse based on the question "Was there ever a time or times in your life when you drank four or more drinks of any kind of alcoholic beverage almost every day?" We defined tobacco use as using tobacco or nicotine in the last 5 days.

We defined depression within NHANES using the Patient Health Questionnaire (PHQ-9). ${ }^{23}$ The PHQ-9 is a nine-item screening instrument that asks questions about the frequency of symptoms of depression and scores them on a scale from 0 to 3. The PHQ-9 has been well validated and is commonly used in clinical settings and research studies to define depression. $^{24}$ We used a score of 10 or higher to define depression. ${ }^{25}$

\section{Statistical Analyses}

We performed all statistical analyses using SAS version 9.3 (SAS Institute Inc., Cary, NC, USA). Within our RHSS sample, we calculated confidence intervals around our point estimates of disease prevalence in adults with ASD using the Clopper-Pearson method to account for the small sample sizes in some cells. ${ }^{26,27}$ Within NHANES and NHIS, we used survey-function procedures (Proc SurveyFreq, Proc SurveyMean) to appropriately weight visits and account for the complex sampling design. We calculated $95 \%$ confidence intervals for prevalence estimates accounting for the complex sampling design of NHANES and NHIS. We used domainfunctions to analyze the subpopulations within each age group. This method accounts for the variability of the entire sample when estimating the variances within the domain subgroups. All values reported met the strict release standards established by the NCHS based on the relative standard error of the point estimate and the absolute number of visits. ${ }^{21,22}$

We subsequently compared the prevalence of health conditions in adults with ASD to the general population. Given two proportions and the confidence interval associated with each proportion, we first calculated the difference between the two proportions. Then we estimated the standard errors for this difference using the calculated confidence intervals and the variance formula for the difference statistic. We normalized the difference statistic using the estimated standard error to obtain the $\mathrm{z}$-score and associated $p$ value for a two-tailed test.

For adults with ASD, we used logistic regression models to examine trends in the prevalence of health conditions across age. For each health condition, we modeled the dependent variable (health condition represented as present/absent) across age groups while adjusting for gender. We included age group as a categorical variable.

We examined factors associated with overall health and functional status in adults with ASD using bivariate and multivariate analyses. We compared proportions with chi square test statistics for general proportions and the Cochran-Armitage test for ordered proportions. We subsequently used logistic regression to examine the independent factors associated with health and functional status. We included age, gender, and IQ in based on clinical significance. We included health conditions with $p<0.2$ on bivariate comparison in the model.

\section{Sensitivity Analyses}

Due to the potential for heterogeneity in data abstraction between the sites, we also performed a subgroup sensitivity analysis including only subjects from the primary care network of practices in Rochester, NY. The prevalence of health conditions in a subsample of subjects from Rochester, NY did not differ from the entire sample (data not shown, but are available upon request).

This study was approved by the University of Rochester Research Subjects Review Board and the protocols used by NHANES and NHIS were approved by the National Center for Health Statistics (NCHS) Institutional Review Board. 


\section{RESULTS}

We examined 255 adult participants with ASD. Table 1 depicts their demographic characteristics. Information about IQ was only available for $55.3 \%$ of the sample, but amongst those with a documented IQ score, $91 \%$ had an intellectual disability with an IQ $<70$. The sample was largely male $(75.3 \%)$, consistent with the male predominance in ASD. The mean age of the sample was 33.6 years and the median age was 31 years. Within each age group, the mean age of adults with ASD was similar to that of the general population in NHANES. For the 18-29 age group, the mean age for the RHSS sample and the general population in NHANES was 24.1 vs. 23.5 years, respectively. Within the 30-39 age group the mean age was

Table 2 Health Conditions in Adults with Autism Spectrum Disorders and in the General Population

\begin{tabular}{|c|c|c|c|c|c|c|c|c|c|}
\hline \multirow[t]{2}{*}{ Health Condition } & \multicolumn{3}{|c|}{ 18-29 years } & \multicolumn{3}{|c|}{ 30-39 years } & \multicolumn{3}{|c|}{$>40$ years } \\
\hline & $\begin{array}{l}\text { ASD* } \\
(N=116)\end{array}$ & $\begin{array}{l}\text { General } \\
\text { Population } \dagger\end{array}$ & $P$ Value & $\begin{array}{l}\text { ASD* } \\
N=67)\end{array}$ & $\begin{array}{l}\text { General } \\
\text { Population } \dagger\end{array}$ & $P$ Value & $\begin{array}{l}\text { ASD* } \\
N=72)\end{array}$ & $\begin{array}{l}\text { General } \\
\text { Population } \dagger\end{array}$ & $P$ Value \\
\hline \multicolumn{10}{|l|}{ Overall Health } \\
\hline Excellent / Good & $80.9 \%$ & $85.7 \%$ & 0.25 & $68.7 \%$ & $86.1 \%$ & 0.004 & $82.9 \%$ & $80.2 \%$ & 0.59 \\
\hline Fair / Poor & $19.1 \%$ & $14.3 \%$ & 0.25 & $31.3 \%$ & $13.9 \%$ & 0.004 & $17.1 \%$ & $20.0 \%$ & 0.56 \\
\hline \multicolumn{10}{|l|}{ Neurologic } \\
\hline Seizure Disorder & $11.2 \%$ & $1.4 \% \ddagger$ & 0.002 & $22.4 \%$ & $1.7 \%+$ & $<0.001$ & $29.2 \%$ & $1.7 \%+$ & $<0.001$ \\
\hline Migraine / Severe Headache & $8.6 \%$ & $17.2 \% \ddagger$ & 0.004 & $4.5 \%$ & $20.5 \% \ddagger$ & $<0.001$ & $0.0 \%$ & $15.1 \%$ & $<0.001$ \\
\hline \multicolumn{10}{|l|}{ Gastrointestinal } \\
\hline Constipation & $19.8 \%$ & $17.2 \%$ & 0.54 & $32.8 \%$ & $23.8 \%$ & 0.14 & $31.9 \%$ & $22.5 \%$ & 0.11 \\
\hline GERD & $23.3 \%$ & - & - & $19.4 \%$ & - & - & $18.1 \%$ & - & - \\
\hline Celiac Disease & $0.0 \%$ & - & - & $0.0 \%$ & - & - & $1.4 \%$ & - & - \\
\hline Bowel Obstruction & $0.0 \%$ & - & - & $4.5 \%$ & - & - & $2.8 \%$ & - & - \\
\hline \multicolumn{10}{|l|}{ Psychiatric } \\
\hline Depression & $16.4 \%$ & $6.4 \% \S$ & 0.007 & $17.9 \%$ & $6.7 \% \S$ & 0.028 & $9.7 \%$ & $7.9 \% \S$ & 0.65 \\
\hline Anxiety disorder & $35.3 \%$ & & - & $22.4 \%$ & $\|$ & - & $31.9 \%$ & $\|$ & - \\
\hline ADHD & $27.6 \%$ & - & - & $9.0 \%$ & - & - & $2.8 \%$ & - & - \\
\hline Schizophrenia or psychosis & $3.5 \%$ & ๆ & - & $3.0 \%$ & q & - & $8.3 \%$ & I & - \\
\hline Bipolar disorder & $7.8 \%$ & - & - & $3.0 \%$ & - & - & $4.2 \%$ & - & - \\
\hline \multicolumn{10}{|l|}{ Heart and Circulatory } \\
\hline Hypertension & $12.9 \%$ & $6.3 \%$ & 0.05 & $10.5 \%$ & $14.7 \%$ & 0.34 & $27.8 \%$ & $38.0 \%$ & 0.071 \\
\hline Hyperlipidemia & $9.5 \%$ & $9.3 \%$ & 0.96 & $32.8 \%$ & $17.5 \%$ & 0.01 & $36.1 \%$ & $44.7 \%$ & 0.151 \\
\hline $\begin{array}{l}\text { Myocardial Infarction } \\
\text { or Stroke }\end{array}$ & $0.0 \%$ & $0.4 \%$ & 0.009 & $0.0 \%$ & $0.8 \%$ & $<0.001$ & $1.4 \%$ & $5.9 \%$ & 0.049 \\
\hline \multicolumn{10}{|l|}{ Pulmonary } \\
\hline Asthma & $17.2 \%$ & $18.4 \%$ & 0.76 & $11.9 \%$ & $14.2 \%$ & 0.6 & $5.6 \%$ & 13.5 & 0.018 \\
\hline Allergies & $39.7 \%$ & $8.4 \%$ & $<0.001$ & $32.8 \%$ & $16.7 \%$ & 0.009 & $29.2 \%$ & $20.5 \%$ & 0.13 \\
\hline COPD \# & $0.0 \%$ & $0.2 \%$ & $<0.001$ & $1.5 \%$ & $0.4 \%$ & 0.64 & $2.8 \%$ & $2.5 \%$ & 0.91 \\
\hline \multicolumn{10}{|l|}{ Endocrine } \\
\hline Diabetes & $3.5 \%$ & $0.8 \%$ & 0.22 & $4.5 \%$ & $2.4 \%$ & 0.52 & $6.9 \%$ & $11.8 \%$ & 0.17 \\
\hline Hypothyroid & $4.3 \%$ & $3.1 \% * *$ & 0.60 & $16.4 \%$ & $4.5 \% * *$ & 0.016 & $13.9 \%$ & $12.6 \% * *$ & 0.77 \\
\hline Hyperthyroid & $0.9 \%$ & & 0.15 & $0.0 \%$ & & $<0.001$ & $4.2 \%$ & & 0.006 \\
\hline \multicolumn{10}{|l|}{ Genito-urinary and Kidney } \\
\hline Urinary incontinence & $4.3 \%$ & $4.0 \%$ & 0.89 & $19.4 \%$ & $8.5 \%$ & 0.039 & $22.2 \%$ & $13.7 \%$ & 0.11 \\
\hline Chronic kidney disease & $0.9 \%$ & $1.0 \%$ & 0.94 & $0.0 \%$ & $0.6 \%$ & $<0.001$ & $1.4 \%$ & $4.6 \%$ & 0.27 \\
\hline \multicolumn{10}{|l|}{ Musculoskeletal } \\
\hline \multirow{2}{*}{\multicolumn{10}{|c|}{ Substance Use }} \\
\hline & & & & & & & & & \\
\hline Tobacco/Nicotine & $5.2 \%$ & $31.9 \% \dagger \dagger$ & $<0.001$ & $3.0 \%$ & $27.5 \% \dagger \dagger$ & $<0.001$ & $2.8 \%$ & $24.5 \%+\dagger$ & $<0.001$ \\
\hline Alcohol Misuse & $0.9 \%$ & $11.9 \%+t$ & $<0.001$ & $0.0 \%$ & $15.1 \%+$ & $<0.001$ & $1.4 \%$ & $18.2 \%+t$ & $<0.001$ \\
\hline \multicolumn{10}{|l|}{ Infectious } \\
\hline STI & $0.9 \%$ & $4.3 \% \S \S$ & 0.027 & $1.5 \%$ & $4.1 \% \S \S$ & 0.292 & $0.0 \%$ & $3.4 \% \S \S$ & $<0.001$ \\
\hline \multicolumn{10}{|l|}{ General } \\
\hline Obesity & $38.8 \%$ & $25.7 \%$ & 0.008 & $43.3 \%$ & $33.9 \%$ & 0.146 & $27.8 \%$ & $37.8 \%$ & 0.076 \\
\hline
\end{tabular}

GERD gastroesphageal disease; ADHD attention deficit hyperactivity disorder; COPD Chronic obstructive lung disease; STI sexually transmitted illness

* Confidence intervals obtained using the Clopper-Pearson method due to small sample sizes in some cells

+ All data are from NHANES 2009-2010 and NHANES 2011-2012 unless otherwise specified

t Data from NHIS 2013

$\S$ Depression defined as have a PHQ9 score of 10 or greater. MEC weights used to calculate weighted estimates

II The 12-month prevalence of generalized anxiety disorder among adults is estimated to be $2.9 \%$ United States. ${ }^{28,29}$ The lifetime risk for generalized anxiety is estimated at $9.0 \%{ }^{28,29}$

II The lifetime prevalence of schizophrenia appears to be approximately 0.3-0.7\%. ${ }^{28,30-32}$ The prevalence of psychotic disorder due to another medical condition has been estimated to range from $0.21 \%$ to $0.54 \%{ }^{28,30-32}$ The lifetime prevalence of all psychotic disorders is estimated to be approximately $3 \% 32$

\# COPD includes emphysema and chronic bronchitis

** Includes any thyroid problem

† Defined as using tobacco or nicotine in the last 5 days

+ Defined as drinking 5 or more drinks per day almost every day

$\S \S$ Defined as having gonorrhea, chlamydia or genital herpes in the past 12 months 
33.8 vs. 34.5 years and within the $40-71$ age group, the mean age was 48.8 vs. 53.7 years, respectively. A total of $4.7 \%$ of the sample was 60 years of age or over.

Table 2 depicts the reported overall health status and health conditions in adults with ASD and in the general population. Participants with ASD reported similar overall health status as the general population across the age groups. Compared to the general population, young adults aged 18-29 with ASD had a substantially higher prevalence of seizure disorder (11.2\% vs. $1.4 \% ; p=0.002)$, depression ( $16.4 \%$ vs. $6.4 \% ; p=0.007)$, hypertension ( $12.9 \%$ vs. $6.3 \% ; p=0.05)$, and allergies ( $39.7 \%$ vs. $8.4 \% ; p<0.001)$. In contrast, young adults with ASD had considerably lower rates of sexually transmitted illnesses (STI) $(0.9 \%$ vs. $4.3 \%$; $p=0.03)$, tobacco use $(5.2 \%$ vs. $31.9 \% ; p<0.001)$, and alcohol misuse $(0.9 \%$ vs. $11.9 \%$; $<0.001)$. Adults 40 and over with ASD similarly had higher rates of seizure disorder $(29.2 \%$ vs. $1.7 \% ; p<0.001)$ and lower tobacco use ( $2.8 \%$ vs. $24.5 \% ; p<0.001)$, and alcohol misuse $(1.4 \%$ vs. $18.2 \%$; $p<0.001)$ compared to the general population.

Table 3 shows the adjusted odds ratios for the trend in the prevalence of heath conditions across the different age groups. Compared to younger adults aged 18-29 years, adults with autism aged 40 years and older had an increased prevalence of seizure disorder (AOR 3.1; $95 \%$ CI 1.5-6.8), constipation (AOR 1.9; 95\% CI 1.0-3.7), hypertension (AOR 2.8; $95 \%$ CI 1.3-6.1), hyperlipidemia (AOR 6.7; 95\%CI 3.0-15.1),

Table 3 Trend of Health Conditions Across Age Groups in Adults with Autism Spectrum Disorders

\begin{tabular}{|c|c|c|c|}
\hline Outcome & $\begin{array}{l}18-29 \\
\text { years } \\
\text { AOR* }\end{array}$ & $\begin{array}{l}30-39 \\
\text { years } \\
\text { AOR* }\end{array}$ & $\begin{array}{l}>40 \text { years } \\
\text { AOR* }\end{array}$ \\
\hline \multicolumn{4}{|l|}{ Overall Health } \\
\hline Excellent / Good & 1.0 & $0.6(0.3-1.2)$ & $1.2(0.6-2.7)$ \\
\hline \multicolumn{4}{|l|}{ Neurologic } \\
\hline Seizure Disorder & 1.0 & $2.1(0.9-4.8)$ & $3.1(1.5-6.8)$ \\
\hline \multicolumn{4}{|l|}{ Gastrointestinal } \\
\hline Constipation & 1.0 & $2.0(1.0-3.9)$ & $1.9(1.0-3.7)$ \\
\hline GERD & 1.0 & $0.7(0.3-1.5)$ & $0.7(0.3-1.4)$ \\
\hline \multicolumn{4}{|l|}{ Psychiatric } \\
\hline Depression & 1.0 & $1.2(0.6-2.8)$ & $0.6(0.2-1.5)$ \\
\hline Anxiety disorder & 1.0 & $0.6(0.3-1.1)$ & $0.9(0.5-1.7)$ \\
\hline ADHD & 1.0 & $0.3(0.1-0.7)$ & $0.1(0.0-0.3)$ \\
\hline $\begin{array}{l}\text { Schizophrenia or } \\
\text { psychosis }\end{array}$ & 1.0 & $0.7(0.1-4.2)$ & $2.4(0.6-8.8)$ \\
\hline Bipolar & 1.0 & $0.3(0.1-1.6)$ & $0.5(0.1-1.9)$ \\
\hline \multicolumn{4}{|l|}{ Heart and Circulatory } \\
\hline Hypertension & 1.0 & $0.9(0.3-2.4)$ & $2.8(1.3-6.1)$ \\
\hline Hyperlipidemia & 1.0 & $6.6(2.8-15.2)$ & $6.7(3.0-15.1)$ \\
\hline \multicolumn{4}{|l|}{ Pulmonary } \\
\hline Asthma & 1.0 & $0.7(0.3-1.6)$ & $0.3(0.1-0.9)$ \\
\hline Allergies & 1.0 & $0.9(0.5-1.7)$ & $0.7(0.4-1.3)$ \\
\hline \multicolumn{4}{|l|}{ Endocrine/Metabolic } \\
\hline Diabetes Type 2 & 1.0 & $1.3(0.3-6.2)$ & $2.1(0.5-8.1)$ \\
\hline Hypothyroid & 1.0 & $3.8(1.2-11.5)$ & $3.3(1.1-10.3)$ \\
\hline \multicolumn{4}{|c|}{ Genito-urinary and Kidney } \\
\hline Urinary incontinence & 1.0 & $5.4(1.8-16.2)$ & $6.4(2.2-18.4)$ \\
\hline General & & & \\
\hline Obesity & 1.0 & $1.2(0.6-2.2)$ & $0.6(0.3-1.1)$ \\
\hline
\end{tabular}

GERD gastroesphageal disease; ADHD attention deficit hyperactivity disorder

* Age was modeled as a categorical variable and adjusted for gender hypothyroidism (AOR 3.3; $95 \%$ CI 1.1-10.3), and urinary incontinence (AOR 6.4; 95 \% CI 2.2-18.4). Most psychiatric conditions occurred at a similar rate across the age groups, but ADHD was less prevalent in adults with autism aged 40 years and older (AOR 0.1; $95 \%$ CI 0.0-0.3).

Within our sample, fewer than half of all adults with ASD were independent with all of the activities of daily living (ADL) (Table 4). Across the age groups, independence with all ADLs decreased among the older age groups. In participants over 40 years old, only $54.2 \%$ were independent with eating, $43.0 \%$ were independent with dressing, and $43.1 \%$ were independent with bathing. In this age group, $4.2 \%$ required a cane or walker and $10.7 \%$ required a wheelchair.

Table 5 demonstrates factors associated with overall health and functional status. Female gender, seizure disorder, gastroesophageal reflux disease (GERD), attention deficit hyperactivity disorder (ADHD), and dental disease were all associated with lower reported health status. Lower IQ, seizure disorder, and depression were associated with worse functional status.

\section{DISCUSSION}

Although ASD is well described in the pediatric literature, this is one of the few studies to examine health conditions and functional status in adults with ASD. ${ }^{14,15,33,34}$ Most notably, we found a considerably higher prevalence of seizure disorders in adults with ASD in all age groups compared to the general population. We also found higher rates of depression, hypertension, and allergies in young adults with ASD, which approached the prevalence of the general population in our older age groups. We also found high rates of anxiety,

Table 4 Functional Ability in Adults with Autism Spectrum Disorders

\begin{tabular}{|c|c|c|c|}
\hline Activity of Daily Living & $\begin{array}{l}18-29 \text { yrs } \\
(N=116)\end{array}$ & $\begin{array}{l}30-39 \text { yrs } \\
(N=66)\end{array}$ & $\begin{array}{l}\geq 40 \text { yrs } \\
(N=72)\end{array}$ \\
\hline $\begin{array}{l}\text { Independent with All ADLs } \\
\text { Eating }\end{array}$ & $50.0 \%$ & $43.3 \%$ & $41.7 \%$ \\
\hline Independent & $55.2 \%$ & $47.5 \%$ & $54.2 \%$ \\
\hline $\begin{array}{l}\text { Supervision of Verbal } \\
\text { Prompt }\end{array}$ & $37.9 \%$ & $41.4 \%$ & $34.7 \%$ \\
\hline $\begin{array}{l}\text { Requires Assistance } \\
\text { or Totally Dependent }\end{array}$ & $6.9 \%$ & $9.1 \%$ & $11.1 \%$ \\
\hline \multicolumn{4}{|l|}{ Dressing } \\
\hline Independent & $51.7 \%$ & $51.5 \%$ & $43.0 \%$ \\
\hline $\begin{array}{l}\text { Supervision of Verbal } \\
\text { Prompt }\end{array}$ & $38.8 \%$ & $34.9 \%$ & $41.7 \%$ \\
\hline $\begin{array}{l}\text { Requires Assistance } \\
\text { or Totally Dependent }\end{array}$ & $9.5 \%$ & $13.6 \%$ & $14.3 \%$ \\
\hline \multicolumn{4}{|l|}{ Bathing and Washing } \\
\hline Independent & $50.0 \%$ & $48.5 \%$ & $43.1 \%$ \\
\hline $\begin{array}{l}\text { Supervision of Verbal } \\
\text { Prompt }\end{array}$ & $37.9 \%$ & $34.8 \%$ & $27.8 \%$ \\
\hline $\begin{array}{l}\text { Requires Assistance } \\
\text { or Totally Dependent }\end{array}$ & $12.1 \%$ & $16.7 \%$ & $29.1 \%$ \\
\hline \multicolumn{4}{|l|}{ Toileting } \\
\hline Independent & $57.8 \%$ & $54.5 \%$ & $52.8 \%$ \\
\hline $\begin{array}{l}\text { Supervision of Verbal } \\
\text { Prompt }\end{array}$ & $30.2 \%$ & $25.8 \%$ & $29.2 \%$ \\
\hline $\begin{array}{l}\text { Requires Assistance } \\
\text { or Totally Dependent }\end{array}$ & $12.0 \%$ & $19.7 \%$ & $18.0 \%$ \\
\hline
\end{tabular}


Table 5 Percent of Adults with Autism Spectrum Disorders in Excellent or Good Health and Independent with Activities of Daily Living

\begin{tabular}{|c|c|c|c|c|c|c|}
\hline \multirow[b]{2}{*}{ Factor } & \multicolumn{3}{|l|}{ Overall Health } & \multicolumn{3}{|l|}{ Functional Status } \\
\hline & Excellent or Good Health & $P \dagger$ & $\begin{array}{l}\text { AOR } \\
\text { (95\% CI) }\end{array}$ & Independent ADLs* & $P \dagger$ & $\begin{array}{l}\text { AOR } \\
(95 \% \text { CI) }\end{array}$ \\
\hline \multicolumn{7}{|l|}{ Age (years) } \\
\hline $18-29$ & $80.9 \%$ & $0.97 \S$ & 1.0 & $50.0 \%$ & $0.24 \S$ & 1.0 \\
\hline $30-39$ & $68.7 \%$ & & $0.5(0.2-1.2)$ & $43.3 \%$ & & $1.6(0.7-3.5)$ \\
\hline 40 and Over & $82.9 \%$ & & $1.4(0.5-3.7)$ & $41.7 \%$ & & $2.3(1.1-5.3)$ \\
\hline \multicolumn{7}{|l|}{ Gender } \\
\hline Male & $82.0 \%$ & 0.01 & 1.0 & $47.9 \%$ & 0.25 & 1.0 \\
\hline Female & $66.7 \%$ & & $0.5(0.2-1.0)$ & $39.7 \%$ & & $1.2(0.6-2.5)$ \\
\hline \multicolumn{7}{|l|}{ IQ } \\
\hline IQ>70(Normal/Borderline) & $92.3 \%$ & $<0.01 \S$ & 1.0 & $69.2 \%$ & $<0.01 \S$ & 1.0 \\
\hline IQ 40-69 (Moderate) & $83.3 \%$ & & $0.4(0.0-3.8)$ & $26.9 \%$ & & $0.1(0.0-0.5)$ \\
\hline IQ $<39$ (Severe / Profound) & $64.0 \%$ & & $0.2(0.0-2.2)$ & $22.0 \%$ & & $0.1(0.0-0.5)$ \\
\hline IQ Not Available & $79.3 \%$ & & $0.3(0.0-3.0)$ & $66.7 \%$ & & $0.8(0.2-3.0)$ \\
\hline \multicolumn{7}{|l|}{ Health Conditions } \\
\hline \multicolumn{7}{|l|}{ Hypertension } \\
\hline No & $79.8 \%$ & 0.14 & 1.0 & $45.1 \%$ & 0.56 & - \\
\hline Yes & $69.2 \%$ & & $0.4(0.2-0.9)$ & $50.0 \%$ & & - \\
\hline \multicolumn{7}{|l|}{ Constipation } \\
\hline No & $76.1 \%$ & 0.19 & 1.0 & $49.2 \%$ & 0.08 & 1.0 \\
\hline Yes & $83.8 \%$ & & $2.9(1.2-6.8)$ & $36.8 \%$ & & $0.9(0.4-1.8)$ \\
\hline \multicolumn{7}{|l|}{ GERD / Ulcer } \\
\hline No & $81.6 \%$ & 0.01 & 1.0 & $45.1 \%$ & 0.92 & - \\
\hline Yes & $66.1 \%$ & & $0.5(0.2-1.0)$ & $49.1 \%$ & & - \\
\hline \multicolumn{7}{|l|}{ Diabetes } \\
\hline No & $78.3 \%$ & 0.78 & & $45.7 \%$ & 0.76 & - \\
\hline Yes & $75.0 \%$ & & - & $50.0 \%$ & & - \\
\hline Hypothyroidism & & & - & & & \\
\hline No & $78.8 \%$ & 0.50 & & $46.3 \%$ & 0.70 & - \\
\hline Yes & $73.1 \%$ & & - & $42.3 \%$ & & - \\
\hline \multicolumn{7}{|l|}{ Seizure Disorder } \\
\hline No & $81.3 \%$ & 0.03 & 1.0 & $50.5 \%$ & $<0.01$ & 1.0 \\
\hline Yes & $62.3 \%$ & & $0.5(0.2-0.9)$ & $26.5 \%$ & & $0.6(0.3-1.3)$ \\
\hline \multicolumn{7}{|l|}{ Migraines } \\
\hline No & $79.1 \%$ & 0.14 & 1.0 & $46.3 \%$ & 0.60 & - \\
\hline Yes & $61.5 \%$ & & $0.5(0.1-1.8)$ & $38.5 \%$ & & - \\
\hline \multicolumn{7}{|l|}{ Depression } \\
\hline No & $77.1 \%$ & 0.33 & - & $42.9 \%$ & 0.02 & 1.0 \\
\hline Yes & $84.2 \%$ & & - & $63.2 \%$ & & $2.3(1.0-5.4)$ \\
\hline \multicolumn{7}{|l|}{ Anxiety } \\
\hline No & $78.7 \%$ & 0.75 & - & $42.6 \%$ & 0.12 & 1.0 \\
\hline \multirow{2}{*}{\multicolumn{7}{|c|}{ Psychosis }} \\
\hline & & & & & & \\
\hline No & $77.9 \%$ & 0.66 & - & $45.7 \%$ & 0.77 & - \\
\hline Yes & $83.3 \%$ & & - & $50.0 \%$ & & - \\
\hline ADHD & & & & & & \\
\hline No & $80.2 \%$ & 0.07 & 1.0 & $43.7 \%$ & 0.11 & \\
\hline Yes & $67.5 \%$ & & $0.3(0.1-0.9)$ & $57.5 \%$ & & $1.1(0.5-2.5)$ \\
\hline Bipolar Disorder & & & & & & \\
\hline No & $77.7 \%$ & 0.48 & - & $44.4 \%$ & 0.05 & \\
\hline Yes & $85.7 \%$ & & - & $71.4 \%$ & & $2.6(0.7-9.6)$ \\
\hline Urinary Incontinence & & & & & & \\
\hline No & $79.4 \%$ & 0.25 & - & $48.9 \%$ & 0.02 & \\
\hline Yes & $70.6 \%$ & & - & $26.5 \%$ & & $0.9(0.4-2.4)$ \\
\hline Dental Disease & & & & & & \\
\hline No & $84.6 \%$ & 0.01 & 1.0 & $50.0 \%$ & 0.03 & 1.0 \\
\hline Yes & $61.4 \%$ & & $0.4(0.2-0.9)$ & $35.2 \%$ & & $1.1(0.6-2.2)$ \\
\hline Obesity & & & & & & \\
\hline No & $77.5 \%$ & 0.73 & - & $44.1 \%$ & 0.45 & - \\
\hline Yes & $79.4 \%$ & & - & $48.9 \%$ & & - \\
\hline
\end{tabular}

*Percent of adults who are independent with all ADLs (eating, dressing, bathing, toileting)

+ Chi Square test unless otherwise specified

+ Logistic model includes age, gender, IQ, and health conditions with $p<0.2$ on bivariate comparison

$\S$ Cochran-Armitage Trend Test

psychosis, and ADHD in adults with ASD, although direct comparative results to the general population were not available. In contrast, we found substantially lower rates of migraine headaches, STI, tobacco use, and alcohol misuse in adults with ASD compared to the general population.
Our results are consistent with prior literature, but provide an expanded view of health conditions and functional status and examine an older age distribution of adults with ASD than previously identified. ${ }^{15,34,35}$ Kohane and colleagues recently examined health conditions in children and young adults with ASD 
through several large quaternary hospitals and found a high prevalence of epilepsy, schizophrenia, and bowel disorders. ${ }^{15} \mathrm{~A}$ similar review of electronic health records by Croen and colleagues found that young adults with ASD experience increased rates of seizures, hypertension, dyslipidemia, sleep disorders, and nearly all psychiatric disorders compared to controls. ${ }^{34} \mathrm{We}$ similarly found higher rates of seizure disorder across all age groups and found high rates of depression, hypertension and allergies in young adults with ASD, although these approached the prevalence of the general population in our older age groups.

We also found that adults with ASD developed several health conditions commonly seen in the general population with increasing age. Hypertension, hyperlipidemia, constipation, hypothyroidism, and urinary incontinence all increased across our age groups. Although these conditions occurred at rates similar to the general population, it is important to recognize that adults with ASD are at similar risk for these common conditions. Unfortunately, adults with intellectual or developmental disabilities frequently face many barriers to accessing health care and receiving recommended treatments for common problems. ${ }^{17,36-40}$ Thus, clinical recognition of these conditions becomes even more critical to providing comprehensive care to adults with ASD.

In contrast to many diseases, we found the prevalence of sexually transmitted illnesses, tobacco use, and alcohol use in adults with ASD were all substantially lower than the general population. This finding is consistent with literature in adults with other neurodevelopmental disorders. ${ }^{41}$ It is possible that the characteristics inherent to ASD limit exposure to situations where tobacco and alcohol use are common. It is also possible that providers are less likely to inquire about alcohol or tobacco use in patients with ASD. Communication barriers, stereotypes about ASD, and methodological limitations of chart abstraction may further limit identification of these conditions.

In addition to examining health conditions, we found that functional status in adults with ASD was substantially lower in older age cohorts. Ultimately, we found that the majority of adults with ASD within our cohort required some assistance with basic ADLs. It is well known that functional decline is associated with aging in both IDD and similar populations. ${ }^{16}$ We found similar results in our population of adults with ASD, but this finding must also be considered within the context of our cohort, in which a considerable percentage of our sample had a concomitant intellectual disability.

Our study has several important limitations and must be interpreted in the context of our sample of adults with ASD. First, IQ status was not available for almost half of our study sample. It is probable that those with an intellectual disability were more likely to have their IQ tested and recorded. Where IQ data was available, a majority had an intellectual disability, which may have skewed our results towards a sample with worsened functional and health status. Second, although we conducted detailed evaluations, our total sample size was limited to 255 adults with ASD. Due to the limited sample size, we may have missed lower prevalence conditions. ${ }^{42}$ It is also possible that medical problems are under-reported in the chart reviews. Third, the RHSS-IV differed from the surveys given to the normative sample; it is possible that this variation either accentuated or attenuated the differences we observed between the ASD and normative groups. Fourth, our sample of adults was weighted towards younger adults. Despite the younger distribution, $28 \%$ of our sample was over 40 years of age, representing one of the oldest distributions of adults with ASD studied to date.

Our sample was also predominantly male, consistent with the gender distribution in ASD. We did not match subjects from the ASD sample to subjects in the national databases to provide comparisons to the broad general population. In addition, we did not have comparative data on functional status within the national databases to compare with our data on adults with ASD. Last, it is possible that a cohort effect was present. Given the increased awareness of ASD over the years, there is a possibility that younger age groups may have included milder cases of ASD that would not have been identified in previous age cohorts.

Our study has several important implications for the care of adults with ASD. Recognition of seizure disorders in adults with ASD is particularly important due to its association with worse overall health status, decreased functional ability, and overall mortality. Mortality studies in ASD have found that epilepsy accounts for a large component of early mortality. ${ }^{43-}$ ${ }^{46}$ Due in part to seizure disorders and accidents, life expectancy is reduced in adults with ASD, ranging from 3 to 6 years shorter for men and 3 to 12 years shorter for women. ${ }^{45,46}$ It is also important to recognize that adults with ASD develop many conditions similar to the general population. Thus, greater advocacy and awareness is needed to ensure that adults with ASD are treated for both conditions more prevalent in ASD and conditions that are commonly encountered with advancing age.

Acknowledgements: This research was supported in part by a subcontract to the University of Rochester from the Rehabilitation Research and Training Center on Aging with Developmental Disabilities (RRTCADD), Department of Disability and Human Development at the University of Illinois at Chicago. The RRTCADD is funded by Grant \# H133B080009 from the US Department of Education, Office of Special Education and Rehabilitative Services, National Institute on Disability and Rehabilitation Research. Ms. Robinson's and Ms. Nobis's efforts were also supported by UCEDD Grant \# 90DD066102 from the US Department of Health and Human Services, Administration on Developmental Disabilities to the University of Rochester also by funds from the Bureau of Health Professions (BHPr), Health Resources and Services Administration (HRSA), and the Department of Health and Human Services (DHHS) under Geriatric Education Centers Grant \#D31HP08811.

This project was also supported by the University of Rochester CTSA award number UL1 TROOO042 from the National Center for Advancing Translational Sciences of the National Institutes of Health. The content is solely the responsibility of the authors and does not necessarily represent the official views of the National Institutes of Health, BHPr, HRSA, DHHS or the US Government.

We gratefully acknowledge the data collection efforts of the following agencies: Ministry of Social Affairs and Social Services, Jerusalem, Israel (Joav Merrick, MD); IRCCS Associazione Oasi Maria SS, Troina, Italy (Serafino Buono, PhD); Lifetime Assistance, Inc., Rochester, NY (Jennifer Stow, RN); St Louis Arc, St. Louis, MO (Mary Anne Tolliver, MPA); Genesee Arc, Batavia, NY (Debora Miller, ABSS); Latham Centers, Brewster, MA (Judy Blum, RN); Upstate Medical Center, Syracuse, NY (Nienke Dosa, MD). 
Conflict of Interest: The authors declare that they do not have any conflicts of interest.

Corresponding Author: Robert J. Fortuna, MD, MPH; Center for Primary Care, Department of Internal Medicine and PediatricsUniversity of Rochester School of Medicine and Dentistry, Rochester, NY, USA (e-mail: Robert_Fortuna@urmc.rochester.edu).

\section{REFERENCES}

1. Kanner L. Autistic disturbances of affective contact. Nerv Child. 1943;2:217-249.

2. Prevalence of Autism Spectrum Disorder Among Children Aged 8 Years Autism and Developmental Disabilities Monitoring Network, 11 Sites, United States, 2010. Morbidity and Mortality Weekly Report (MMWR), Centers for Disease Control and Prevention. 2014.

3. Mesibov GB, Shea V. Evidence-based practices and autism. Autism. 2011;15(1):114-133. doi:10.1177/1362361309348070.

4. Munshi KR, Gonzalez-Heydrich J, Augenstein T, D'Angelo EJ. Evidence-based treatment approach to autism spectrum disorders. Pediatr Ann. 2011;40(11):569-574. doi:10.3928/00904481-20111007-00904408.

5. Myers SM. Management of autism spectrum disorders in primary care. Pediatr Ann. 2009;38(1):42-49.

6. Philippe P, Scholl JM, Jacques J. Comorbidity in autism spectrum. Psychiatr Danub. 2010;22(Suppl 1):S158-160.

7. Johnson CP, Myers SM. Identification and evaluation of children with autism spectrum disorders. Pediatrics. 2007;120(5):1183-1215.

8. Mukaetova-Ladinska EB, Perry E, Baron M, Povey C. Ageing in people with autistic spectrum disorder. Intl J Geriatr Psychiatr. 2012;27(2):109-118.

9. Happe F, Charlton RA. Aging in autism spectrum disorders: a minireview. Gerontology. 2012;58(1):70-78.

10. Davidson PW, Janicki MP, Ladrigan P, Houser K, Henderson CM, Cain NN. Associations between behavior disorders and health status among older adults with intellectual disability. Aging Ment Health. 2003;7(6):424-430.

11. Haveman M, Perry J, Salvador-Carulla L, et al. Ageing and health status in adults with intellectual disabilities: results of the European POMONA II study. J Intellect Dev Disabil. 2011;36(1):49-60. doi:10.3109/13668250. 13662010.13549464.

12. Lugnegard T, Hallerback MU, Gillberg C. Psychiatric comorbidity in young adults with a clinical diagnosis of Asperger syndrome. Res Dev Disabil. 2011;32(5):1910-1917. doi:10.1016/j.ridd.2011.1903.1025.

13. Mattila ML, Hurtig T, Haapsamo H, et al. Comorbid psychiatric disorders associated with Asperger syndrome/high-functioning autism: a community- and clinic-based study. J Autism Dev Disord. 2010;40(9):1080-1093. doi:10.1007/s10803-10010-10958-10802.

14. Nicolaidis C, Kripke CC, Raymaker D. Primary care for adults on the autism spectrum. Med Clin N Am. 2014;98(5):1169-1191.

15. Kohane IS, McMurry A, Weber G, et al. The co-morbidity burden of children and young adults with autism spectrum disorders. PLoS One. 2012;7(4), e33224.

16. Sullivan WF, Berg JM, Bradley E, et al. Primary care of adults with developmental disabilities: Canadian consensus guidelines. Can Fam Physician. 2011;57(5):541-553.

17. Nicolaidis C, Raymaker D, McDonald $\mathbf{K}$, et al. Comparison of healthcare experiences in autistic and non-autistic adults: a cross-sectional online survey facilitated by an academic-community partnership. J Gen Intern Med. 2013;28(6):761-769.

18. Davidson PH, Henderson CM, Janicki MP, Robinson LM, Bishop KM, Wells A, Garroway J, Wexler O. Ascertaining health-related information on adults with intellectual disabilities: Development and field testing of the Rochester Health Status Survey. J Pol Pract Intellect Disabil. 2008;5(1):12-23.

19. Manual for the Rochester Health Status Survey-IV (RHSS-IV) University of Rochester School of Medicine and Dentistry. Available at: https://www. urmc.rochester.edu/urmcmedia/childrens-hospital/developmental-disabilities/padd/documents/rhssivmanualfinal12-30-2008_002.pdf. Accessed 7/29/2015.

20. Rochester Health Status Survey-IV. 2009; Available at: https://www.urmc. rochester.edu/medialibraries/urmcmedia/childrens-hospital/developmental-disabilities/padd/documents/rhssiv_us_002.pdf. Accessed 7/29/2015.
21. National Center for Health Statistics. National Health and Nutrition Examination Survey (NHANES). 2014; Available at: http://www.cdc.gov/ nchs/nhanes.htm. Accessed 7/29/2015.

22. National Center for Health Statistics. National Health Interview Survey (NHIS). 2014; Available at: http://www.cdc.gov/nchs/nhis.htm. Accessed $7 / 29 / 2015$.

23. Kroenke K, Spitzer RL, Williams JB. The PHQ-9: validity of a brief depression severity measure. J Gen Intern Med. 2001;16(9):606-613.

24. Gilbody S, Richards D, Brealey S, Hewitt C. Screening for depression in medical settings with the Patient Health Questionnaire (PHQ): a diagnostic meta-analysis. J Gen Intern Med. 2007;22(11):1596-1602.

25. Manea L, Gilbody S, McMillan D. Optimal cut-off score for diagnosing depression with the Patient Health Questionnaire (PHQ-9): a meta-analysis. CMAJ : Can Med Assoc J=J de l'Assoc Med Can. 2012; 184(3):E191-196.

26. DasGupta A, Brown DL, Cai T. Interval estimation for a binomial proportion. Stat Sci. 2001;16(2):101-117.

27. Vollset S. Confidence Intervals for a Binomial Proportion. Stat Med. 2006; 12:809-824.

28. Association: AP. American Psychiatric Association: Diagnostic and Statistical Manual of Mental Disorders. 5th ed. Arlington, VA: American Psychiatric Association; 2013.

29. Kessler RC, Petukhova M, Sampson NA, Zaslavsky AM, Wittchen HU. Twelve-month and lifetime prevalence and lifetime morbid risk of anxiety and mood disorders in the United States. Int $\mathrm{J}$ Methods Psychiatr Res. 2012;21(3):169-184.

30. Bogren M, Mattisson C, Isberg PE, Nettelbladt P. How common are psychotic and bipolar disorders? A 50-year follow-up of the Lundby population. Nordic J Psychiatr. 2009;63(4):336-346.

31. McGrath J, Saha S, Chant D, Welham J. Schizophrenia: a concise overview of incidence, prevalence, and mortality. Epidemiol Rev. 2008;30:67-76.

32. Perälä J, Suvisaari J, Saarni SI, Kuoppasalmi K, Isometsä E, Pirkola S, et al. Lifetime prevalence of psychotic and bipolar I disorders in a general population. Arch Gen Psychiatry. 2007;64(1):19-28.

33. Perkins EA, Berkman KA. Into the unknown: aging with autism spectrum disorders. Am J Intellect Dev Disabil. 2012;117(6):478-496.

34. Croen LA, Zerbo O, Qian Y, Massolo ML, Rich S, Sidney S, Kripke C. The health status of adults on the autism spectrum. Autism : Int $J$ Res Pract. Apr 24 2015. doi:10.1177/1362361315577517.

35. Tyler CV, Schramm SC, Karafa M, Tang AS, Jain AK. Chronic disease risks in young adults with autism spectrum disorder: forewarned is forearmed. Am J Intellect Dev Disabil. 2011;116(5):371-380.

36. Lee JC, Hasnain-Wynia R, Lau DT. Delay in seeing a doctor due to cost: disparity between older adults with and without disabilities in the United States. Health Serv Res. 2012;47(2):698-720.

37. Nicolaidis C, Raymaker DM, Ashkenazy E, et al. "Respect the way I need to communicate with you": Healthcare experiences of adults on the autism spectrum. Autism : Int J Res Pract. Apr 162015.

38. Krahn GL, Hammond L, Turner A. A cascade of disparities: health and health care access for people with intellectual disabilities. Ment Retard Dev Disabil Res Rev. 2006;12(1):70-82.

39. Anderson LL, Humphries K, McDermott S, Marks B, Sisirak J, Larson S. The state of the science of health and wellness for adults with intellectual and developmental disabilities. Intellect Dev Disabil. 2013;51(5):385-398.

40. Bruder MB, Kerins G, Mazzarella C, Sims J, Stein N. Brief report: the medical care of adults with autism spectrum disorders: identifying the needs. J Autism Dev Disord. 2012;42(11):2498-2504.

41. Bejerot S, Nylander L. Low prevalence of smoking in patients with autism spectrum disorders. Psychiatry Res. 2003;119(1-2):177-182.

42. Robertson J, Hatton C, Emerson E, Baines S. The impact of health checks for people with intellectual disabilities: an updated systematic review of evidence. Res Dev Disabil. 2014;35(10):2450-2462.

43. Gillberg C, Billstedt E, Sundh V, Gillberg IC. Mortality in autism: a prospective longitudinal community-based study. J Autism Dev Disord. 2010;40(3):352-357.

44. Pickett J, Xiu E, Tuchman R, Dawson G, Lajonchere C. Mortality in individuals with autism, with and without epilepsy. J Child Neurol. 2011;26(8):932-939.

45. Shavelle RM, Strauss D. Comparative mortality of persons with autism in California, 1980-1996. J Insurance Med. 1998;30(4):220-225.

46. Shavelle RM, Strauss DJ, Pickett J. Causes of death in autism. J Autism Dev Disord. 2001;31(6):569-576 